\title{
FOLLOWERS RESPONSES ON THE INFLUENCE OF FEEDBACK CREDIBILITY AS A MODERATOR ON THE RELATIONSHIP BETWEEN CONSTRUCTIVE FEEDBACK AND SELF-EFFICACY OF TEACHING
}

\author{
Ying-Leh, Ling \& Abdul Ghani Kanesan Abdullah \\ School of Educational Studies, Universiti Sains Malaysia \\ lingyingleh@gmail.com, agk@usm.my
}

\begin{abstract}
This study aimed to identify the effect of feedback on the credibility of the source towards constructive feedback and selfefficacy of teaching. Specifically, the objective of this study was to determine whether the credibility of the source of feedback be the moderator of the relationship between the constructive feedback and self-efficacy of teaching. In this study, a total of 411 lecturers from three premier polytechnics and two polytechnics which achieved excellent recognition through polyrate took part. Data for this study were collected through a questionnaire which was adapted from previous researchers' questionnaire. Finding shows that higher academic qualification does have an effect on feedback credibility. Hypothesis testing is done by using multiple regression analysis and hierarchical multiple regression analysis. Findings have shown the constructive feedback and credibility of feedback have an influence on self-efficacy of teaching. In addition, the findings also indicate the credibility of the feedback was moderator of the relationship between the constructive feedback and self-efficacy of teaching. In terms of implications, middle leaders in educational organizations should enhance the skills, knowledge, and credibility in giving constructive feedback to shape and improve self-efficacy among his followers.
\end{abstract}

\section{Keywords}

Feedback credibility, Constructive feedback, Self-efficacy of teaching.

\section{Academic Discipline And Sub-Disciplines}

Management and leadership education

\section{TYPE (METHOD/APPROACH)}

Quantitative research and survey

\section{Council for Innovative Research}

Peer Review Research Publishing System

Journal: International Journal of Research in Education methodology

Vol. 7, No.2

ijremeditor@gmail.com

www.ijrem.com 


\section{INTRODUCTION}

In line with the government's effort to achieve high-income country, Malaysia needs 1.5 million employees in Technical and Vocational Education Training (TVET) by the year 2020. This is because the global markets are now showing an increase in demand for semi-skilled technicians and those in the field of technical and vocational education. Thus, polytechnics as one of the higher education institutions is not immune from playing an important role in producing the graduates who actually meet the needs of various industries that are being developed. In this case, polytechnics aims to supply more than 50 percent of the 680 thousand skilled workers with diploma qualification in 2020. Therefore, polytechnics requires higher self-efficacious lecturers in teaching to meet the demands of economic transformation in 2020. Self-efficacy is very emphasized among the polytechnic lecturers quality criteria becaue this group of people is said to be more likely to choose an effective coping strategy and continuous in the task entrusted (Zajacova, Lynch, \& Espenshade, 2005).

In facing the life paradigm displacement in the 21st century, leaders must take the initiative to undertake the development of potential followers, especially in the aspect of organizational psychology. In this case, the psychological aspects of the organization emphasized in line with the opinion of Jex and Britt (2008) in which a leader should focus on his psychology as a psychological measure individual behavior, specifically to identify how his influence organizational effectiveness. Thus, educational organizations should play a role in a more comprehensive and not just produce products to meet the needs of the industrial market. Organizations need to realize that not only provide employment to its employees. To ensure the quality of human capital generated, leaders must focus on the input (feedback) and process (environment response) in the organization. Thus, in shaping the behavior of workers who are more committed and creative, setting up the environment feedback in the workplace should not be ignored. This is because the feedback in the workplace is believed to have an effect on the formation of workers' self-efficacy.

\section{LITERATURE REVIEW}

\section{Feedback credibility}

Feedback delivered by leaders considered as cognitive and behavioral mechanisms that are important to give effect to the performance of his followers. In identifying the relationship between leaders and followers, the credibility of the feedback source is one of the important factors that should be considered. Feedback credibility was conceptualized as expertise and trust of the source of feedback. This is further supported by studies of Steelman et al. (2004) show a more accurate feedback, valuable, and likely to be accepted and positive feedback when the source is reliable. In addition, Boyce, Jackson, and Neal (2010) also emphasizes an effective leader is an individual who can be trusted and has extensive career experience. This is due to receive a response within the context of relationships that can be trusted to provide an important platform for change and leadership development itself occurred (Grant, Green, \& Rynsaardt, 2010). Reviews Sue-Chan and Latham (2004) shows the importance of the credibility of the coach in improving the effectiveness of behavioral and academic achievement of MBA players. Moreover, the study Bozer, Perros, and Santora (2014) also found that the feedback credibility has a positive relationship with the effectiveness of the guidance given by the leader to the follower. Thus, it is believed credibility of the feedback source in the context of this study, which refers to the expertise and trust the source of feedback to influence self-efficacy.

\section{Constructive feedback}

Feedback needed to advance their careers in the organization of followers. Followers need to know the views of leaders on their performance from time to time. Indeed, individuals not only need to get feedback formal or informal than even their leaders must actively seek it (Ashford \& Cummings, 1985). Thus, constructive feedback on performance needs to be communicated to every follower's behavior consistent with organizational goals and strengthen their skills and career interests of efficiency followers (Huselid, 1995). It aims to help followers understand their roles and responsibilities with in the organization. In addition, Steelman et al. (2004) considers the constructive feedback as the frequency of positive feedback as a compliment though Kluger and Ashley (1998) deny praise as constructive feedback due to the low impact on individual. Review Sun, Aryee, and Law (2007) has found followers believe that the organization wanted to help them when the feedback given to improve personal effectiveness in the tasks entrusted. Further studies by Sommer and Kulkarni (2012) also found that supervisors who use more constructive feedback are more respected by their employees and employees see more opportunity in his career progress for him.

\section{Self-efficacy of Teaching}

Self-efficacy is important in education. In the context of education, self-efficacy refers to the ability of students to instructors affect output. Educational organizations require a group of trainers who have high self-efficacy for performing the responsibilities entrusted. According to Friedman and Kass (2002), self-efficacy of teachers are teachers' perceptions on their ability to perform professional tasks required and regulate relations involved in the process of teaching students and conducting organizational tasks that are part of the political and social processes in organization. Accordingly, Ciani, Summers, and Easter (2008) said self-efficacy is associated with changes in behavior as a result of the impact on student motivation. Hoy and Tschannen-Moran (2003) describes the self-efficacy of teachers reflect what teachers can do in certain situations and not what has been achieved by them or why they achieve in the past. In other words, self-efficacy beliefs influence the selection of action, thought patterns and emotional response to a situation that teachers faced. 


\section{RESEARCH METHODOLOGY}

This study was conducted using a survey method. Respondents consisted of 411 lecturers working in three premier polytechnics and two polytechnics who received the outstanding achievement as a whole through polyrate, including the academic standards and quality management through the recognition of the polytechnic. The instrument used was a questionnaire which was adapted from an instrument used by the Steelman et al. (2004) and Tschannen-Moran and Hoy (2001). The questionnaire is divided into four parts, namely Part A to obtain demographic information, Part B (9 items) also diagnose the extent of organization support on feedback process, Part $C$ (12 items) on the perception of self-efficacy teaching. A total of 600 questionnaires were distributed and 411 sets of questionnaires only be collected with a questionnaire return rate as high as 68.5 percent.

\section{RESEARCH FRAMEWORK}

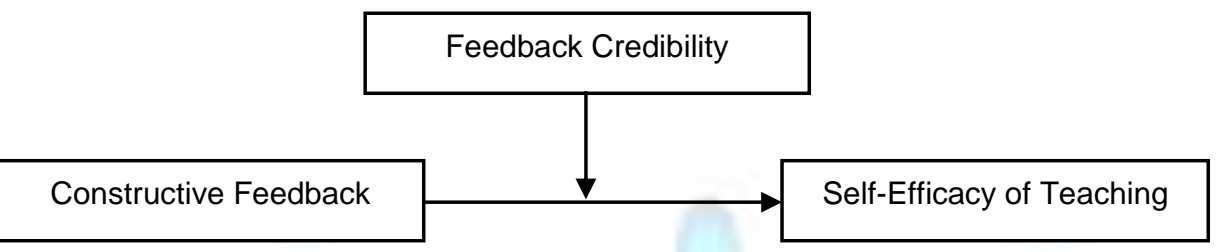

\section{RESEARCH HYPOTHESIS}

$\mathrm{Ho}_{1}$ : There are significant differences between the credibility of the feedback source across the highest academic qualification.

$\mathrm{Ho}_{2}$ : $\quad$ Feedback credibilty affects the self-efficacy of teaching.

$\mathrm{Ho}_{3}$ : Constructive feedback affects the self-efficacy of teaching.

$\mathrm{Ho}_{4}$ : Feedback credibility has the effect of moderating the relationship between the constructive feedback and selfefficacy of teaching.

\section{RESEARCH FINDINGS}

\section{Respondent profile}

The respondents consisted of 411 lecturers who are currently serving in the five polytechnics which have received international recognition for polytechnic through polyrate. Such recognition has to give polytechnics have the potential to be able to achieve the objectives of the transformation agenda at the fastest rate heartbeat involvement and support from various parties. In addition, the polytechnic was also seen as a system of management and human resource capacity competitive with the characteristics of excellence that can change the current paradigm of polytechnics. It is a catalyst for change in the overall system of polytechnic education and training in Malaysia. Of these, 151 respondents (36.7 percent) were male lecturers while 260 respondents (63.3 percent) were female lecturers. Based on academic qualifications, a total of 6 persons ( 1.5 percent) had a doctoral degree, 145 persons (35.3 per cent) would be eligible bachelors, 16 persons (3.9 percent) qualified diploma, while a majority of respondents holds a bachelor's degree with a concentration of 244 people (59.4 percent) .

\section{Table 1. Respondent profile $(\mathrm{N}=411)$}

\begin{tabular}{llcc}
\hline Variable & Category & Total & Percent (\%) \\
\hline Gender & Male & 151 & 36.7 \\
Highest Academic Qualification & Female & 260 & 63.3 \\
& Diploma & 16 & 3.9 \\
& Degree & 244 & 59.4 \\
& Master & 145 & 35.3 \\
& PhD & 6 & 1.5 \\
\hline
\end{tabular}

\section{Hyphotesis 1}

$\mathrm{Ho}_{1}$ : There are significant differences between the credibility of the feedback source across the highest academic qualification.

A one-way between subjects ANOVA was conducted to compare the effect of the highest academic qualification on feedback credibility in diploma, degree, master, and doctorate conditions. There was a significant effect of feedback credibility on the highest academic qualification for the four conditions $[F(3,405)=3.45, p=.017]$. Post hoc comparisons using the Tukey HSD test indicated that the mean score for the doctorate condition $(M=4.67, S D=1.325)$ was significantly different than the diploma condition $(M=5.75, S D=.940)$, degree condition $(M=5.74, S D=.758)$ and master condition $(M=5.66, S D=.891)$. Taken together, these results suggest that higher academic qualification really do 
have an effect on feedback credibility. Specifically, our results suggest that when an individual has higher qualifications, his credibility as a source of feedback will be increased and upgraded. However, it should be noted that higher qualification must be gained in order to see an effect.

\section{Hypothesis 2}

$\mathrm{Ho}_{2}$ : $\quad$ Feedback credibilty affects the self-efficacy of teaching.

The results of multiple regression analysis of Table 2 shows that the credibility of the source of feedback significantly contributed 3.3 percent of the variance of changes to teaching self-efficacy. The results of the examination of the beta coefficient $(\beta)$ indicates the credibility of feedback sources constructive feedback $(\beta=.18, p<.05)$ have significant and positive influence on teaching self-efficacy. These results support the hypothesis 2 which states the credibility of the feedback sources positively influ affects self-efficacy of etaching. This finding explains credibility of feedback sources positively and significantly affect self-efficacy of teaching.

Table 2. Coeficient value $\beta$ for the influence of feedback credibility towards self-efficacy of teaching

\begin{tabular}{lc}
\hline Indenpendent Variable & Dependent Variable Self-Efficacy of Teaching \\
\hline Feedback Credibility & $.18^{*}$ \\
$\mathrm{R}^{2}$ & .033 \\
Adjusted $\mathrm{R}^{2}$ & .031 \\
F Value & $14.07^{\star}$ \\
Durbin Watson & 1.91 \\
\hline
\end{tabular}

\section{Hypothesis 3}

$\mathrm{Ho}_{3}$ : Constructive feedback affects the self-efficacy of teaching.

Findings from Table 3 shows the constructive feedback variables significantly contributed 7.7 percent of the variance of changes to teaching self-efficacy. The results of the examination of the beta coefficient $(\beta)$ shows the constructive feedback $(\beta=.28, p<.05)$ have significant and positive influence on teaching self-efficacy. Further, these results support the hypothesis 3 which states the constructive feedback effect on teaching self-efficacy in positiif. This finding explains the constructive feedback positively and significantly affect teaching self-efficacy.

Table 3. Coeficient value $\beta$ for the influence of constructive feedback towards self-efficacy of teaching Indenpendent Variable Dependent Variable Self-Efficacy of Teaching

Constructive Feedback $\quad .28^{\star}$

$\mathrm{R}^{2} \quad$.077

Adjusted $\mathrm{R}^{2} \quad .075$

$\begin{array}{ll}F \text { Value } & 34.35^{*}\end{array}$

Durbin Watson

\section{Hypothesis 4}

$\mathrm{Ho}_{4}$ : Feedback credibility has the effect of moderating the relationship between the constructive feedback and selfefficacy of teaching.

Hierarchical multiple regression analysis was used to measure the feedback credibility effects as a moderator of the relationship between the constructive feedback with self-efficacy of teaching. The findings from Table 4 have shown constructive feedback is a significant and positive impact on self-efficacy of teaching through the first step. Next, in a second step, the findings show the reliability of the source of feedback do not have a significant impact on teaching selfefficacy. In the third step, Table 3 shows the effect of the interaction has a positive and significant $(\beta=1.040, p<.05)$.

Podsakoff, MacKenzie, and Bommer (1996) noted moderator effects can be identified by a significant change in $R^{2}$ during the regression analysis. The findings from Table 4 have shown changes in $R^{2}$ of the first step to the second step was significant $\left(\Delta R^{2}=.002\right)$ and then from the second step to the third step is also significant $\left(\Delta R^{2}=.022\right)$ and obtain the $F$ ratio was significantly $(F=15: 22, p<.05)$. Thus, these findings show the credibility of the source of feedback affect moderator of the relationship between the constructive feedback with self-efficacy of teaching. These results support the hypothesis 4 stating the credibility of the source of feedback have moderating effects on the relationship between the constructive feedback and teaching self-efficacy. 
Table 4. Result of hierarchical multiple regression analysis: the moderator effects of feedback credibility $(\mathrm{N}=411)$

\begin{tabular}{lccc}
\hline Variable & $\begin{array}{c}\text { Standard Beta } \\
\text { (Model 1) }\end{array}$ & $\begin{array}{c}\text { Standard Beta } \\
\text { (Model 2) }\end{array}$ & $\begin{array}{c}\text { Standard Beta } \\
\text { (Model 3) }\end{array}$ \\
\hline $\begin{array}{l}\text { Independent variable } \\
\text { Constructive Feedback (MBM) }\end{array}$ & $.278^{*}$ & $.256^{*}$ & -.446 \\
Moderator variable & & .039 & $-.416^{*}$ \\
Feedback Credibility (KBS) & & & $1.040^{*}$ \\
Interaction effect & & .079 & .101 \\
MBM $^{*}$ KBS & .077 & .074 & .094 \\
\hline$R^{2}$ & .075 & .079 & .101 \\
Adjusted R & .077 & $17.38^{*}$ & $15.22^{*}$ \\
The changes of $R^{2}$ & $34.35^{*}$ & 1.89 & 1.92 \\
The changes of F & 1.89 & & \\
Durbin Watson & & & \\
\hline
\end{tabular}

\section{RESEARCH DISCUSSION}

These findings demonstrate the constructive feedback has a significant influence on self-efficacy of teaching. Feedback building contributed 7.7 percent to the variance of changes to teaching self-efficacy. This finding is consistent with studies conducted by Sun, Aryee, and the Law (2007) and Sommer and Kulkarni (2012) showed that feedback used to improve the ability of self-build successful careers of employees in undertakings. Further, the findings also found that the credibility of the source of feedback have significant effects on teaching self-efficacy. Feedback credibility contributed 3.3 percent to the variance of changes to teaching self-efficacy. This finding is consistent with the findings of Bozer et al. (2014) and Sue-Chan and Latham (2004), which concludes the credibility of the source of feedback to improve the effectiveness of individual behavior.

In addition, the results also show the reliability of the source of feedback serves as a moderator of the relationship between the constructive feedback and teaching self-efficacy. The results showed interaction effects constructive feedback and feedback to improve the reliability of sources of variance contribution of teaching self-efficacy. The results of this study support the findings Bozer et al. (2014) which states that the credibility of the person giving the feedback has been positive relationship toward another individual's work performance thereunder. This is because when the credibility of the feedback formed to give feedback, followers have the confidence to face relationship with the leader.

\section{RESEARCH IMPLICATION}

This study focuses on some of the implications of the existence of feedback in the workplace. According Bozer et al. (2014), the credibility of the leader should be identified in giving constructive feedback and positive to his followers as a determinant of communication between leaders and followers guidance. Thus, the credibility of the source feedback (leader) will determine the extent of his use of information and experiences of leaders through the coaching transfer in the form of coaching output and better quality. Therefore, the credibility of middle leaders in educational organizations in particular should be enhanced through expertise and mandate for change and the ability to shape the quality of selffollowers in the organization of work.

\section{CONCLUSION}

The results show there is influence of constructive feedback and credibility of feedback sources on self-efficacy of teaching. In addition, the credibility of the source of feedback also affect the relationship between the constructive feedback and self-efficacy of teaching. Therefore, middle leaders in educational organizations in particular should demonstrate its credibility in giving feedback constructively and positively to the followers in order to improve teaching selfefficacy among his followers. This will help generate human capital that can meet the industrial needs from time to time.

\section{REFERENCES}

[1] Ashford, S. J., \& Cummings, L. L. (1985). Proactive feedback seeking: The instrumental use of the information environment. Journal of Occupational Psychology, 58(1), 67-79.

[2] Boyce, L. A., Jackson, J. R., \& Neal, L. J. (2010). Building successful leadership coaching relatiionships: Examining impact of matching criteria in a leadership coaching program. Journal of Management Development, 29(10), 914-931.

[3] Bozer, G., Sarros, J. C., \& Santora, J. C. (2014). Academic background and credibility in executive coaching effectiveness. Personnel Review, 43(6), 881-897.

[4] Ciani, K. D., Summers, J. J., \& Easter, M. A. (2008). A "top-down" analysis of high school teacher motivation Contemporary Educational Psychology, 33, 533-560. 
[5] Friedman, I. A., \& Kass, E. (2002). Teacher self-efficacy: A classroom-organization conceptualization. Teaching and Teacher Education, 18, 675-686.

[6] Grant, A. M., Green, L. S., \& Rynsaardt, J. (2010). Developmental coaching for high school teachers: Executive coaching goes to school. Consulting Psychology Journal: Practice and Research, 62(3), 151-168.

[7] Hoy, W. K., \& Tschannen-Moran, M. (2003). The conceptualization and measurement of faculty trust in schools: The omnibus T-scale. In Hoy, W. K., \& Miskel, C. G. Studies in leadership and organizing school (pp. 181-208). Greenwich. CT: Information Age Publishing.

[8] Huselid, M. A. (1995). The impact of human resource management practices on turnover, productivity, and corporate financial performance. Academy of Management Journal, 38(3), 635-672.

[9] Kluger, A. N., \& DeNisi, A. (1998). Feedback interventions: Towards the understanding of a double-edge sword. Current Directions in Psychological Science, 7, 67-72.

[10] Sommer, K. L., \& Kulkarni, M. (2012). Does constructive performance feedback improve citizenship intentions and job satisfaction? The roles of perceived opportunities for advancement, respect, and mood. Human Resource Development Quarterly, 23(2), 177-201. doi: 10.1002/hrdq

[11] Steelman, L. A., Levy, P. E., \& Snell, A. F. (2004). The feedback environment scale: Construct definition, measurement, and validation. Educational and Psychological Measurement, 64(1), 165-184.

[12] Sue-Chan, C., \& Latham, G. P. (2004). The relative effectiveness of external, peer, and self-coaches. Applied Psychology: An International Review, 53(2), 260-278.

[13] Sun, L., Aryee, S. \& Law, K. S. (2007). High-performance human resource practices, citizenship behavior, and organizational performance: A relational perspective. Academy of Management Journal, 50(3), 558-577.

\section{Author' biography}

Ying-Leh, Ling currently doing his PhD with his research interests in management, leadership education and organization psychological.

Abdul Ghani Kanesan Abdullah is an associate professor in the School of Educational Studies, Universiti Sains Malaysia. His research interests include the educational management and administration, education leadership and school development. 